\title{
Propriedade e contrato social Um breve incurso no relacionamento entre estado e associações de trabalhadores a partir de C. B. Macpherson
}

\author{
Neiva Afonso Oliveira ${ }^{1}$
}

A apresentação de uma análise da Thesis de Crawford Macpherson ${ }^{2}$ interessa-nos por duas razões prioritárias. A primeira delas diz respeito à temática desenvolvida. Trata-se de uma descrição acerca do relacionamento entre estado e corporações ou associações voluntárias que desemboca, em última instância, na vigilância exercida pelo estado sobre as corporações. A grande questão de

\footnotetext{
${ }^{1}$ Doutora em Filosofia Política pela Pucrs, é professora na Univ. Católica de Pelotas e no Programa de Pós-Graduação em Filosofia da Univ. Federal de Pelotas; pesquisa sobre Ética, Filosofia Política e Políticas Públicas. Participou de missão de trabalho ligada ao Projeto de Pesquisa intitulado Movimentos sociais e luta por direitos de cidadania: uma comparação Brasil-Alemanha Publicou Rousseau e Rawls: contrato em duas vias (Pucrs, 2000) e diversos artigos, entre os quais Da crítica ao liberalismo a uma criptoética liberal: os contratualismos de Rousseau e Rawls (Dissertatio, n. 10, 1999), A Teoria da Justiça de John Rawls: pressupostos de um neo-contratualismo hipotético (Sociedade em Debate, 1999), Cidadania e participação política: uma contribuição ao debate a partir de C. B. Macpherson (Sociedade em Debate, 2000). Endereço: neiva@ufpel.edu.br

${ }^{2}$ Crawford Brough Macpherson (1911-1987) foi um crítico da democracia liberal e incentivador da democracia participativa. É autor, entre outros, de A teoria política do individualismo possessivo (1979), Ascensão e queda da justiça econômica (1985) e A democracia liberal (1978), todos traduzidos para o português.
}

Civitas, Porto Alegre, v. 4, nº 1, jan.-jun. 2004 
fundo político-filosófico, que inspira uma tal descrição, é a da crítica à visão contratualista das relações políticas e sociais. Em segundo lugar, a apreciação dos argumentos do professor canadense em relação a tal temática interessa-nos sob o ponto de vista da compreensão dos motivos que o levaram a abandonar ou, pelo menos, nunca mencionar a inicial tentativa de sistematização de suas idéias. A hipótese fraca que poderia representar resposta a esta última questão está vinculada ao fato de sua tese não estar publicada, o que tornaria impossível uma referência sua a este escrito. Fruto de compilação de dezesseis textos, o trabalho final (Master's thesis) consta de mais de trezentas páginas e conferiu ao autor o título de Doctor of Science in Economics, DSc (Econ).

A maior preocupação do autor em sua Master's thesis é focalizar e contrapor a teoria e prática do movimento de associações de trabalhadores na Inglaterra relativamente à estrutura legal imposta pela relação estatal, através da legislação e de decisões judiciais. Em sua origem, as associações de trabalhadores (trade unions) representam associações voluntárias, assim como as igrejas, movimentos religiosos, entidades de negócios, esportivas e outros clubes, partidos políticos, agências caritativas e associações de profissionais, como médicos e advogados. Alguns desses setores, eventualmente, são legalmente reconhecidos pelos governos que, então, impõem a eles determinadas exigências. Entretanto, outros tantos setores permanecem não incorporados ao sistema legal. O reconhecimento das associações de trabalhadores ou sindicatos foi obtido através do Trade Union Act, em 1871. Macpherson acrescenta, ao final do texto, uma discussão sobre um outro tipo de associação voluntária (a Associação Médica Britânica) a fim de juntar elementos contrastantes com seu argumento.

A ênfase sobre as atribuições do estado reflete, nos escritos macphersonianos, a influência de seu professor, Harold Laski, autor de livros sobre diferentes concepções de soberania e de estado encontradas na história e sobre o desenvolvimento dessas doutrinas desde o século XVI, incluindo um texto geral denominado The State in theory and practice (1935). O rol de referências em sua tese inclui, entre outros, textos de Tawney (The choice before Labour Party) de 1933, panfleto da Liga Socialista, de Franz Neumann, um escrito denominado Trade unionism, democracy, dictatorship (1934) e também um material panfletário do Comitê Educacional das Associações de Trabalhadores. O tema ligado ao relacionamento entre associações voluntárias e o estado, entretanto, havia sido tratado algum tempo antes, na literatura acadêmica, com abordagem da teoria política e jurídica por dois eminentes estudiosos, J. N. Figgis e F. W. Maitland, cujos pontos de vista são mencionados brevemente pelo professor canadense.

$\mathrm{O}$ enfoque dado por Macpherson à relação entre associações de 
trabalhadores e o estado na Inglaterra constitui um olhar sobre alguns dos pontos principais das mais importantes partes da legislação e de decisões judiciais significativas, após 1871. O objetivo da tese é mostrar que o fio condutor do relacionamento entre o estado e as associações voluntárias é o princípio da propriedade:

[...] a tendência geral da lei e suas variações em diferentes épocas só são compreensíveis admitindo-se que, regulando as competências e o status dos sindicatos, o estado agiu consistentemente a partir de um único princípio. Vê-se que este princípio é a manutenção da base essencial do sistema industrial vigente, ou seja, a estrutura das relações de propriedade neste sistema e, de modo mais geral, a preservação das instituições sociais que servem para manter estas relações de propriedade em toda a sociedade. (Macpherson, 1935, p. 14)

Em relação às palavras do autor citadas acima, podemos afirmar que as instituições sociais estão baseadas na estrutura de compreensão das relações de propriedade. À medida que avançamos na leitura do texto, as conexões entre os conceitos-chave tornam-se mais claras. O estado é o agente interlocutor de interesses sociais dominantes e determinados pelo modelo de relações de propriedade. Portanto, em suas ações, o estado estará completamente motivado pelo objetivo da proteção às relações de propriedade. Parece claro também que, em sua tese, Macpherson não pretendeu colocar proposições que incluem uma sentença inicial do tipo "teste" de um argumento teórico ou empírico. Antes, trata-se de proposições que servem como pressuposições ou postulados para o exame das relações entre associações civis e estado. Além disso, seu exercício especulativo não torna claro que o estado tenha suas ações guiadas por um único princípio, pois não há uma investigação acerca de um elenco de possíveis candidatos a princípio último a motivar as relações entre o estado e entidades associativas.

Admitimos aqui uma explicação realista para tal omissão: a exposição de Macpherson estaria dominada por um objetivo pragmático, qual seja, a tentativa de averiguar, a partir da base de sua investigação histórica, que posicionamentos assumiriam as associações de trabalhadores, durante aquele período de iminentes mudanças. Nas páginas iniciais o professor canadense esclarece: "Considerarei o provável desenvolvimento futuro dos sindicatos, tanto no estado capitalista quanto no estado socialista que eles almejam." (Macpherson, 1935, p. 8) Conforme podemos notar, a opção entre capitalismo ou socialismo permeia o todo da exposição dos argumentos na "Thesis". Naturalmente, esta era uma postura que o autor compartilhava com muitos intelectuais europeus de esquerda, para quem a aproximação do fascismo tornou urgente a libertação do capitalismo através dos movimentos socialistas de base. Uma pequena minoria ainda preconizava uma redenção através do Partido Comunista. 
Ao desenvolver seu tema central, Macpherson focalizou o que denominou a "anômala posição" das uniões de trabalhadores resultante da submissão a leis e a decisões judiciais, desde 1871, época em que o efeito obtido foi o de colocar as associações civis em um nível inferior, entre as associações voluntárias não incorporadas ao sistema e às corporações. No período anterior a 1871, quando somente a lei comum era aplicada, a maioria das associações e atividades a elas ligadas eram formalmente ilegais e encaradas como combinações de limitação de ocupações, uma vez que, sob a lei ordinária, a liberdade de comércio, por exemplo, era interpretada como operação não restritiva ao mercado de trabalho entre compradores e vendedores da força de trabalho. A Lei das Associações de Trabalhadores, datado de 1871, liberava as associações dessas restrições da lei ordinária, no exato momento em que elas buscavam o reconhecimento de determinadas metas, como por exemplo, a luta por melhores salários. As associações de trabalhadores obtiveram, através deste instrumento jurídico, reconhecimento legal como associações voluntárias, o que a elas também permitiu adquirir propriedade e angariar fundos. A Lei de 1913 formalizaria esse procedimento através da garantia do assim chamado Register of Friendly Societies, possibilidade de registrar ou enquadrar uma associação de trabalhadores nos propósitos da lei. Não havia, entretanto, qualquer coação legal que obrigasse ao registro. Aquelas associações que não obtivessem o registro continuariam a receber tratamento de associações voluntárias não incorporadas ao sistema legal, o que significaria, entretanto, menores privilégios.

Quarenta anos após 1871, porém, a pertença às associações e a força econômica das mesmas cresceram rapidamente e, no período anterior à Primeira Guerra Mundial, o governo viu-se forçado a reconhecer, pela primeira vez, o poder político do movimento associativo e do Partido Trabalhista. Em torno dos debates parlamentares sobre a Trades Disputes Act (Lei das Disputas dos Sindicatos, 1906), o professor canadense faz a seguinte constatação: “A oposição, assim como o governo, concordava que os sindicatos eram naquele momento uma parte indispensável do sistema industrial e eram uma força a favor da ordem e da paz na indústria." (1935, p. 86)

A principal razão para esta revelação está em que as Associações de Trabalhadores haviam começado a demonstrar seu potencial de barganha e estreavam uma manifestação de poder que desembocaria em busca de reconhecimento institucional com o fim de obtenção de acordos salariais, condições de trabalho e controle de surgimento de greves e protestos. A lei de 1913 referia-se a um número específico de artigos, especialmente a uma formulação de regras úteis para compilação e uso prático das associações, como por exemplo, a permissão da utilização de taxa dos associados em causas políticas. Mais relevante do que esta permissão, entretanto, era o 
reconhecimento de princípios contidos na lei de 1906, notadamente aqueles relativos à negociação oficial dos interesses coletivos da classe trabalhadora. Os debates parlamentares da época revelam, segundo o professor canadense, a convicção, compartilhada por todos os envolvidos, de que as associações de trabalhadores não eram tão-somente aceitáveis; constituíam, isto sim, partes necessárias da estrutura industrial, e também deveriam ser encaradas como elemento garantidor de estabilidade entre os trabalhadores. Em sua Thesis, Macpherson cita-nos um discurso parlamentar que corrobora sua análise:

Não acredito que alguém, conhecendo um pouco das condições de trabalho neste país, irá questionar o fato que nos sindicatos encontra-se a melhor classe de trabalhadores, e que quanto mais apoio e força forem dados aos corpos que unem esses homens, melhor será para a estabilidade das indústrias deste país. (apud Macpherson, 1935, p. 115)

Com efeito, um novo contrato social estava sendo estabelecido e um outro interesse social havia sido identificado. Um terceiro elemento, como se poderia dizer, estava interpondo-se entre as duas pontas já existentes e representadas pelo capital e pelo trabalho: o interesse público. Promover a idéia de um interesse público com o objetivo de atingir a base e uma certa linearidade nas relações industriais alcançou determinada proeminência durante os debates parlamentares de 1906, quando foi posta em discussão uma condição de permanência e de antagonismo não restritivo entre capitalistas e trabalhadores. Por esta época, face ao crescimento econômico e político do trabalho, começava a tomar corpo o argumento que sugeria que tal antagonismo, provavelmente, viria a prejudicar e até mesmo destruir muito do progresso social e econômico alcançado na Inglaterra da época. Em 1906, ainda não estava suficientemente claro que a "solução" para uma tal oposição (capital versus trabalho) seria a intermediação do estado; entretanto, as sementes indicativas desta crença estavam lançadas. Macpherson interpreta este desenvolvimento como uma nova instância do estado que mantém, entretanto, sua identidade essencial enquanto elemento de preservação da estrutura das relações de propriedade. William Leiss, no entanto, embora eminente estudioso da obra de Macpherson, parece não compreender o que, de fato, está em jogo. Considera a argumentação macphersoniana muito vaga e baseada em pressupostos não suficientemente legitimados. Para o comentador, permanecem questões em aberto. Ele não considera suficientemente esclarecida a razão pela qual, ao aperfeiçoar-se a noção de interesse público em oposição à irrestrita competição entre capital e trabalho, estará o estado imperiosamente a atender aos interesses do primeiro. Paralelamente a esta questão, indaga se não seria mais lógico pensar que o estado serviria melhor aos interesses do capital ao simplesmente enfraquecer o aumento de poder do trabalho. Quem poderia afirmar, com segurança, que uma tal ofensiva falharia? Além disso, observando 
a situação a partir de um outro ângulo, William Leiss pergunta ainda se não se poderia compreender este desenvolvimento, que concedeu ao trabalho organizado um lugar permanente à mesa de negociações, como sendo de interesse tanto do próprio trabalho organizado quanto de outros tipos de interesses sociais. E finaliza, a fim de evidenciar os pressupostos em que Macpherson apóia sua avaliação, que só seria legítimo desacreditar que tal movimento serviria aos interesses do trabalho se presumíssemos que o único verdadeiro objetivo do movimento trabalhista consiste em tornar-se o interesse social dominante, conforme a visão socialista tradicional, e ainda que esse novo contrato social impediria que este objetivo fosse alcançado. Estas, no entanto, não parecem ser pressuposições razoáveis. (Leiss, 1989, p. 34-35)

O próprio texto do professor Macpherson nos fornece indicações de que durante todo o próximo quarto de século, na Inglaterra, a idéia do interesse público como algo apartado e superior aos objetivos de qualquer outro grupo social manteve-se, na teoria e na prática, no movimento de associação e em seu braço político, o Partido Trabalhista. Por exemplo, durante os debates do chamado Emergency Powers Act de 1920, quase todo o Partido Trabalhista sustentou a visão de que o público, nas palavras de Macpherson, deveria ser encarado como um terceiro partido, não vinculado aos empregadores e trabalhadores, cujo interesse deveria ser prioritariamente defendido pelo estado. Durante esse mesmo período, as ações e políticas das associações de trabalhadores demonstravam sua adesão cada vez maior ao mesmo modelo, principalmente no que se refere a forçar o estado (através de seu poder político e econômico) a admitir o dever de sustentar e, gradualmente, melhorar o nível de benefícios socioeconômicos através de salários mínimos, condições de trabalho, pensões, seguro-desemprego, enfim, situações de bem-estar social e mínimos sociais maiores, operacionalizando essas condições de tal forma a se tornarem universalmente aplicáveis. Em outras palavras, não se trataria de o trabalho substituir o capital como o interesse social dominante, mas, antes, gradualmente, procurar diminuir sua estável e intocada dominação sobre a vida social. Este estratagema, por confirmação de nosso autor, foi utilizado durante a Greve Geral de 1926 e não pretendeu, de forma alguma, a supressão do capitalismo. A greve representaria uma tática extrema, justificada pelas circunstâncias do momento, porém inadequada para questionar toda estratégia em que estivera baseado o movimento representado pela cooperação com organizações de empregadores, com uma visão de racionalização de indústrias em escala nacional, seguridade para os trabalhadores e co-gestão na empresa. Uma tal proposta de mudança implicaria participação, em níveis nacionais, em torno de consultas futuras entre capital e trabalho, incluindo medidas para aprimorar a eficiência econômica de certas indústrias. De acordo com o pensamento de muitos intelectuais, isto ainda seria possível, mesmo com um 
eventual triunfo do socialismo mas, em se tratando de prioridades, esta meta de longo alcance deveria, claramente, estar subordinada aos mais imediatos fins: primeiro, proteger os níveis de vida atingidos pelos trabalhadores em termos de benefícios sociais e, em segundo lugar, buscar avanços em torno dessas mesmas conquistas. Cabe aqui salientar que a efetivação dessa estratégia deveria estar congenialmente ligada à repulsão de meios violentos. Quando do iminente colapso econômico, os membros do encontro anual do Congresso das Associações de Trabalhadores, em 1934, deliberaram em torno de liberdades políticas e democráticas e contra a violência e ditadura, num movimento que poderia ser assemelhado ao que a literatura contemporânea tem tratado como juridificação da cidadania. ${ }^{3}$ Neste sentido, o professor canadense, inclusive, questiona-se acerca da solidez da base das Associações dos Trabalhadores em ratificar conteúdo e sustentação programáticos do Partido Trabalhista. Em se tratando de conteúdo programático, o Partido Trabalhista defendia a planificação e centralização da economia, nacionalização das indústrias primárias e do sistema financeiro.

Uma outra faceta deste contrato social está representada no desejo de o estado, aos poucos, assumir responsabilidades em relação a um número crescente de necessidades relevantes da vida dos trabalhadores, que eram anteriormente supridas pelas associações, como no caso de benefícios para desempregados, seguros-saúde, apoio legal a acordos coletivos, seguros por acidente e outros. Macpherson salienta que, inevitavelmente, tais garantias, ao serem concedidas pelo estado, enfraqueceriam o movimento em medida equivalente, uma vez que o interesse do trabalhador individual em proteger e aumentar tais benefícios resta transferido de uma arena (associações) para outra (processo político).

Quando o estado, enquanto agente do interesse social, aceita a responsabilidade por um conjunto de condições - no caso, condições de trabalho - que envolvem uma enorme parcela da vida dos cidadãos e que, anteriormente, eram tratadas, a partir de um ponto de vista legal, como matéria privada, ele passa a encarar tais condições como elementos do processo político. Enquanto outras instituições, dentre as quais as associações, devem manter sua responsabilidade pela tarefa de melhorar as condições de trabalho através de táticas de grupos de pressão sobre os políticos, seus próprios membros descobrem que agora eles mesmos, em muitos aspectos, têm um interesse direto no resultado dos acontecimentos políticos ao passo que um interesse apenas indireto no destino do movimento de associações. Aquilo que

\footnotetext{
${ }^{3}$ A esse respeito, ver, em Flickinger (2003), o capítulo $O$ direito de cidadania - uma faca de dois gumes.
} 
contemporaneamente já denominamos "aparelhamento"4 dos movimentos sociais organizados da sociedade civil, tem suas raízes plantadas no conseqüente desdobramento da ação do estado - protetor dos interesses civis. Escrevendo sobre esta inevitável conseqüência, Macpherson (1935) afirma: “... a força intensa e o espírito ativo dos sindicatos não sobreviverão a esta mudança sem serem diminuídos." (p. 232)

A necessidade de barganha que Macpherson avista como enfraquecimento do movimento social tem, entretanto, uma outra face que poderia ser identificada como, no caso em questão, uma politização da sociedade civil com relação ao tema condições de trabalho. Embora o professor canadense não afirme assim, a sua observação anterior parece estar concordante com esta nossa constatação. Além disso, ao politizar as condições de trabalho, a sociedade civil poderia, por extensão e conseqüência, também politizar o tema das relações de propriedade, uma vez que a sociedade pode atuar como um freio à legitimidade da propriedade e das relações nela implicadas. O estado, por seu turno, atua em benefício das classes proprietárias e do interesse que lhes diz respeito. Um tal argumento terá sustentação na medida em que levamos em conta que a escolha recai sobre as classes sociais e define-se, em última instância, por uma opção entre capitalismo e socialismo. No primeiro, os meios de produção e, portanto, o aspecto determinante da vida social e política, são apropriados por um pequeno grupo e a ele pertencem como propriedade privada. A essência do segundo, por outro lado, está representada pela socialização dos meios de produção, como um conjunto coletivo de bens produzidos em benefício de todos cidadãos (traduzido este benefício em posse, gerenciamento de bens pelo estado, por cooperativas de trabalhadores, por comunidades locais ou, na versão anarquista, por intermédio de associações espontâneas, sem o exercício da autoridade estatal). Entretanto, esta possibilidade de escolha, tão evidente por si só para tantos membros de várias classes sociais em muitas partes do mundo nos séculos XIX e XX, foi excluída como boa em grande parte da esfera do capitalismo avançado e gerenciado (Europa Ocidental e América do Norte). A partir desse pano de fundo, não caberá sequer mencionarmos a tão propalada polarização. William Leiss menciona esta mudança de perspectiva insinuada pelo professor canadense, já

\footnotetext{
${ }^{4}$ Empregamos o termo aparelhamento para designar a utilização das formas organizativas da sociedade civil para cumprir papel de aparelhos ideológicos, de acordo com a conceituação desenvolvida por Louis Althusser em Aparelhos ideológicos de estado. Assim encontramos afirmado em Althusser (1985): "Designamos pelo nome de aparelhos ideológicos do estado um certo número de realidades que apresentam-se ao observador imediato sob a forma de instituições distintas e especializadas." (p. 68) Mais adiante, Althusser indica sua linha geral de atuação: "Todos os aparelhos ideológicos de estado, quaisquer que sejam, concorrem para o mesmo fim: a reprodução das relações de produção, isto é, das relações de exploração capitalistas.” (p. 78)
} 
na década de 1930, ao afirmar que “... na sociedade contemporânea, não temos nem propriedade privada dos meios de produção, nem propriedade socializada, senão que propriedade politizada." (Leiss, 1989, p. 38) Isto significa afirmar a impossibilidade de pensar capitalismo e socialismo nos moldes tradicionais do século XIX e implica poder asseverar que, no futuro, de igual forma não os identificaremos enquanto modelos de sociedade. Entretanto, haverá condições de, segundo Leiss (1989), alcançarmos uma forma híbrida, nascida da longa e histórica tensão entre os dois.

Seguindo o roteiro traçado por Macpherson, todavia, podemos afirmar que tendo escrito sua tese em 1935, não seria a sua argumentação inaceitável quando assume que a polarização capitalismo-socialismo representara os limites da real escolha política disponível. Embora isto não esteja clara e abertamente dito em sua Thesis, consta das entrelinhas. Um exemplo deste enfoque estaria no capítulo relativo à Associação Médica Britânica quando afirma: "Onde quer que no futuro recaia seu interesse real, entre uma sociedade capitalista ou socialista, não é de surpreender que no presente eles acreditem que seu interesse seja a manutenção de uma sociedade capitalista." (1935, p. 295)

Entretanto, uma terceira via havia emergido na década anterior, não podendo, assim, o professor Macpherson desconsiderar o fascismo como um rearranjo de forças dispostas a resolver a oposição entre capital e trabalho. À medida que avança a análise macphersoniana, torna-se clara a possibilidade de uma solução fascista na Inglaterra, à base de sua evidente inquietação em relação ao pacto social iminente entre capital, trabalho e estado.

Durante algum tempo, antes de 1935, o movimento sindical havia buscado tornar-se membro em um contrato social e barganhar o futuro do desenvolvimento industrial com representantes do capital, sob os auspícios da autoridade estatal que assumiria responsabilidade direta com programas relacionados a condições de trabalho e benefícios sociais. Além disso, tivesse o Partido Trabalhista obtido êxito, teria trazido amplos setores financeiros e industriais para a propriedade ou controle direto do estado, fortalecendo, assim, através da influência do movimento sindical sobre o partido, a parte do trabalho nesta relação tripartida. Macpherson era detentor da firme convicção de que esta seria uma situação alta e intrinsecamente instável. Utilizando-nos de uma expressão do professor canadense, esta relação deveria desenhar um estado "semi-socialista", uma ordem política que dificilmente desembocaria em um "socialismo pleno". A instabilidade dar-se-ia, em grande parte, devido à possibilidade de que as medidas implementadas pudessem ser suficientes para amedrontar completamente a classe proprietária, sem, porém, destituí-la de suas posses ou privilégios. 
Mesmo contando com uma dificuldade metodológica que o cenário enleado da época lhe impunha, C. B. Macpherson aponta três fatores relacionados à situação da classe proprietária que poderiam, naquela conjuntura, contribuir decisivamente para a não implantação desse estado semi-socialista. Primeiramente, esta classe poderia "... manter um amplo controle sobre as fontes da opinião pública” (1935, p. 240), referindo-se, provavelmente, à imprensa. Em segundo plano, mas não menos importante, como grupo isolado de interesse, continuaria a ser o mais influente na indústria. Em terceiro lugar, o autor acena com o influxo da classe proprietária sobre a petite bourgeoisie. Embora Macpherson não utilize esta expressão exatamente nesse contexto (usa-a na obra Burke, p. 64), acentua que os pequenos proprietários, por seu turno, também seriam levados a temer a ascensão de um estado semi-socialista. Desta maneira, o autor conclui:

Se a incidência conjunta desses três fatores resultasse na queda do governo trabalhista através de formas democráticas, o governo seguinte, na tentativa de tornar segura a regulamentação da propriedade, encontraria uma estrutura industrial cuja forma apressaria a transformação para um estado fascista e um movimento sindical sem força suficiente para resistir a esta mudança. E é provável que no estágio de desenvolvimento social e industrial que houvesse sido alcançado, nenhuma outra técnica senão o fascismo seria suficiente para assegurar tanto a continuação da produtividade industrial quanto a manutenção do controle do estado pela classe proprietária. (1935, p. 240).

Devemos admitir que este não era um cenário totalmente improvável, dado o curso posterior das tendências e acontecimentos. Quando o declínio do Labour Government realmente ocorreu, em 1951, tendo o conceito histórico como um todo mudado, o que sobrou daquele script não se efetivou.

Para fins de nossa argumentação em torno da implicação da Thesis no restante da obra filosófico-política do autor canadense, não estaremos interessados na forma como um tal cenário desmoronou. Deveremos, sim, estar especialmente atentos para a possibilidade de determinar o que este cenário, de uma forma ou de outra, delineou e influenciou em termos de possibilidades históricas. Em outras palavras, uma apreciação da Thesis nos dá uma exata medida de sua formação intelectual e nos é fundamental por diferentes e várias razões. Primeiro, é interessante perceber que em seu primeiro experimento como jovem teórico e comentador de temas de maior relevância, ligados à teoria social e política, ele tenha encaminhado sua exposição teorética tão explicitamente em direção a um fim pragmático, notadamente para a avaliação das possibilidades de sucesso do fascismo na Inglaterra. Em segundo lugar, as premissas inerentes a seu ponto de partida, assim como também a forma como conceitos-chave são utilizados em sua primeira e maior aventura teórica, constituem indicadores de grande porte em sua construção teórica posterior. A 
principal premissa do conteúdo do argumento macphersoniano é a constante demonstração da existência de duas possibilidades; trata-se, pois, de uma argumentação do tipo "either-or", caracterizada pela consciência de que qualquer possibilidade de mudança social precisa levar em conta a tensão entre opostos polarizados.

Conforme sugerimos anteriormente, não constitui novidade o fato de que um jovem teórico-político, detentor de inclinações humanísticas pudesse, em 1935, definir o tema de direções futuras de mudança social como variáveis oscilantes entre capitalismo ou socialismo. Também não é surpreendente, dado o grande impasse no qual se encontravam as sociedades ocidentais, que a adesão a um desses pontos de sustentação garantia um seguro e inquestionável apoio no esforço de elaboração de seu constructo teórico. De qualquer modo, uma forma de argumentação baseada em escolhas de alternativas polarizadas constitui uma marca teórica de todo trabalho posterior do professor canadense. Podemos citar, por exemplo, o contraste muito utilizado pelo autor entre força de desenvolvimento (development power) e força aquisitiva (acquisitive power) em Democratic theory (1973). Em Rise and fall of economic justice (1985), Macpherson apresenta as possibilidades contemporâneas de um futuro desenvolvimento social, em termos de duas opções básicas: um estado corporativista que abalaria o processo democrático, por uma lado, e, por outro, um estado representante das forças democráticas que tomaria para si o controle do governo, transcendendo e transformando nosso capitalismo gerencial atual. A opção de sugerir situações antagônicas estará presente também em The economic penetration of political theory (1978), onde a referência é apresentada entre a sociedade denominada pelo mercado (market-dominated society) versus sociedade não dominada pelo mercado (non-market dominated society); a primeira, evidentemente, representa aquela na qual estamos vivendo; a natureza da segunda, porém, não se encontra especificada. Um tal tipo de exposição freqüentemente funciona como um "limpa-trilhos" e pode ter o objetivo de clarear a paisagem intelectual a fim de que a novidade possa florescer. Nos exemplos de opções polarizadas apresentadas, as características de alternativas para a sociedade e, até mesmo, de uma sociedade indicada pelo contraste da que vivemos, estão tão esquematicamente colocadas que dificilmente saber-se-ia viável sua efetivação.

Existe um importante aspecto no qual a forma e o conteúdo da Thesis pressagiam o estilo intelectual de todo seu trabalho posterior. Trata-se do conceito relacionado às relações de propriedade, que constitui o fundamento de seu primeiro experimento teórico e que, recidivamente, aparece em seus escritos posteriores. Como exemplos do que afirmamos, existem pequenos 
ensaios sobre o tema escritos, nos anos $70 .{ }^{5} \mathrm{O}$ tratamento dado ao problema da propriedade, entretanto, é extremamente interessante do ponto de vista de uma ilustração antecipada, utilizada pelo teórico político como conceito-chave que serviria mais como ponto de referência do que como algo a ser dissecado. $\mathrm{O}$ conceito propriedade e possíveis relações nele imbricadas será utilizado na Thesis e, de resto, em seus escritos posteriores, como elo de ligação e referência em torno do argumento em direção ao qual desejaria avançar. Apesar da repetida utilização da expressão "estrutura de relações de propriedade" e construções similares ao longo das trezentas páginas da tese, não estaremos mais próximos, ao final, daquilo que o autor salienta como elementos constituintes de sua estrutura. Em outras palavras, não há menção ao tipo de propriedade a que se refere, sequer à importância relativa dos diversos tipos de posse (de terras, seguros etc.), à distribuição social da riqueza, aos modelos de herança, à fluência dos investimentos na Inglaterra e noutros países, ou às mudanças com relação ao tema da propriedade, nem nestas nem em outras dimensões.

Eventualmente, esta metodológica indiferença em relação a detalhes pormenorizados, poderia representar um ônus elevado. No capítulo conclusivo da Thesis, Macpherson, enfaticamente, afirma que a noção implícita de estrutura de propriedade faz com que a sociedade seja o que ela é. Acompanhando este argumento conclusivo sobre a propriedade como fator inspirador das relações sociais, o professor canadense reprisa sua pressuposição maior: “... a função precípua do estado é a proteção da sociedade que ele conhece: uma sociedade baseada numa determinada estrutura das relações de propriedade." (1935, p. 308) Até aqui, a referência havia sido feita somente em relação à Inglaterra. Ao partir da seguinte afirmação, aprendemos que aquela pressuposição passa a ser geral:

Não é somente numa sociedade capitalista que o estado existe principalmente para salvaguardar o sistema existente de relações de propriedade. Igualmente, esta é a função do estado em qualquer outro tipo de sociedade que já se conheceu. Isto não é menos verdadeiro na Rússia de hoje do que em qualquer país onde a sociedade seja baseada na instituição da propriedade privada dos meios de produção. (1935, p. 308)

Segue-se a esta menção a referência à possibilidade utópica de uma sociedade futura, justa, na qual ninguém estaria interessado em alterar a

\footnotetext{
${ }^{5}$ The liberal politics of John Locke (1971), Social credit: the English origins (1974) The economic penetration of political theory: some hypotheses (1978), Liberty and property: political ideology in Eighteenth-Century Britain (1979).
} 
distribuição dos direitos de propriedade. Neste ponto, onde seus argumentos mais claramente alinham-se às posições dos partidos comunistas da época, Leiss (1989) não lhe poupa críticas. Para o comentador, atualmente, a proposição de tal generalização - aplicável a todos os tipos conhecidos de sociedades - seria, certamente, de utilidade limitada. E acrescenta que, se tomássemos em consideração o argumento sobre as relações de propriedade nas páginas iniciais da Thesis, o acompanhamento de uma tal argumentação tornar-se-ia enfadonho e inútil. "Na verdade, se tomássemos por seu valor aparente, os próprios esforços do autor nas 300 páginas precedentes teriam sido uma elaboração tediosa e absolutamente desnecessária de uma verdade já conhecida e estabelecida." (p. 43) Trata-se de uma pressuposição em relação à qual o teórico, no desejo de colocá-la em primeiro plano, adquire ímpeto questionador. Imbuída deste impulso inicial está a reflexão que o professor canadense faz a seguir:

O exemplo da U.R.S.S. mostra que a forma totalitária não é menos necessária numa sociedade socialista nova e ainda insegura do que numa sociedade capitalista ameaçada [como a Itália, a Alemanha e a Áustria]. Pois, como dissemos, o estado, em qualquer sociedade, é principalmente o guardião do sistema de relações de propriedade na sociedade em questão; e portanto, em qualquer sociedade, precisa de poder para a exclusão de todas as outras associações, na medida em que esta estrutura seja ameaçada. (1935, p. 320-321)

Leiss (1989), entretanto, acredita não ser assim tão óbvia a necessidade de um estado totalitário para proteger a estrutura das relações de propriedade existentes na União Soviética por volta de 1930, estivesse ou não tal estrutura ameaçada a partir do exterior de suas fronteiras. Ao contrário, o estado stalinista, para ele, esteve muito próximo de destruir a economia e a sociedade da União Soviética.

Ainda não nos cabe levar a cabo uma crítica aprofundada sobre a possibilidade de o professor canadense estar certo ou errado em relação a seus prognósticos. Ao contrário, não seria conveniente, a partir da Thesis, sendo este um escrito pioneiro, envidar esforços no sentido de vasculhar controvérsias ou tópicos através dos quais poderíamos polemizar com o autor. Foi nosso propósito trazer à luz duas questões: primeiro, aludir à forma de argumentação de Macpherson; em segundo lugar, e de forma mais direta, entretanto, arrostar a questão do relacionamento entre estado e movimentos sociais. Com relação ao primeiro aspecto, a expressão assim denominada "relações de propriedade", embora surja como central na argumentação aqui, constitui-se como o ambiente no qual sua argumentação principal - as imbricações da teoria e prática do movimento de associações de trabalhadores no socialismo da Inglaterra - é apresentada. Isto não significa, todavia, que o conceito não seja importante para o autor, uma vez que, de maneira recidiva, volta à análise da questão da 
propriedade. Na Thesis, a expressão conceitual "relações de propriedade" serve a uma função específica, qual seja a de colocar em destaque uma argumentação acerca do significado da história e da influência relacional entre as associações de trabalhadores para os próprios socialistas. A habilidade de empreendimento e exercício de argumentação, destrezas características vinculadas aos teóricos políticos, são atributos mostrados na Thesis pelo professor canadense e que, posteriormente, em trabalhos futuros, serão aprimorados em função de um refinamento metodológico. A essência de sua argumentação, conforme já iniciada na Thesis, consiste em empregar um conceito-chave ou um conjunto de alternativas polarizadas que, por si só, constituem o pano de fundo sobre o qual os demais conceitos recairão. A melhor amostra do emprego de uma tal metodologia ocorre com sua conhecida e famosa obra The political theory of possessive individualism na qual a marca teórica individualismo possessivo, que empresta o título à obra, é definida apenas nas duas páginas finais. Em uma anterior descrição sobre o pensamento político do século XVII, aquele conceito serve como pano de fundo através do qual o cenário pode ser avaliado como um terreno já bem explorado.

Finalizando, é preciso retornar às motivações originárias desse trabalho. De início, afirmamos que uma das razões prioritárias de nosso interesse na Master's Thesis de C. B. Macpherson relaciona-se à discussão das relações entre estado e movimentos sociais. A hipótese que nos orientou era de que, no caso analisado pelo professor canadense, o relacionamento entre estado e corporações ou associações voluntárias desemboca, em última instância, na vigilância exercida pelo estado sobre as corporações. Deste modo, interessavanos mostrar um dos importantes e decisivos limites da concepção filosóficopolítica contratualista, que leva ao pacto interesses materiais antagônicos. Com efeito, percorridos os argumentos do autor, foi possível evidenciar que Macpherson detecta uma "posição anômala" no interior do relacionamento entre estado e associações voluntárias, ou seja, constata que, na origem, as associações de trabalhadores são declaradamente autônomas, porém, na medida em que concordantes com o estabelecimento de um contrato social perfeitamente condizente com o status liberal-capitalista, caminham em direção à sua institucionalização e à profissionalização de suas lideranças e membros. Tal movimento desemboca em uma incorporação de suas demandas à lógica do sistema liberal. Portanto, aquilo que hoje denominamos juridificação dos direitos de cidadania pode ser encontrado também como uma intuição inicial do professor canadense, intuição não plenamente desenvolvida, mas que pode perfeitamente ser localizada em sua desconfiança com relação ao fio condutor do relacionamento entre o estado e as associações voluntárias: a propriedade privada.

\section{Referências}


Althusser, Louis. Aparelhos ideológicos de estado: nota sobre os aparelhos ideológicos de estado (AIE). 4. ed. Trad. Walter José Evangelista e Maria Laura Viveiros de Castro. Rio de Janeiro: Edições Graal, 1989. 128 p. (Biblioteca de ciências sociais; v. n. 25).

Flickinger, Hans-Georg. Em nome da liberdade: elementos da crítica ao liberalismo contemporâneo. Porto Alegre: Edipucrs, 2003. 174 p.

Leiss, William. Dilemmas of Liberalism and Socialism. New York: St. Martin's Press, 1989. 152 p. (New World Perspectives).

Macpherson, Crawford Brough. A democracia liberal. Trad. Nathanael C. Caixeiro. Rio de Janeiro: Zahar, 1978. 118 p.

—_. A teoria política do individualismo possessivo. Trad. Nelson Dantas. Rio de Janeiro: Paz e Terra, 1979. 318 p.

- Ascensão e queda da justiça econômica e outros ensaios. Trad. Luiz Alberto Monjardim. Rio de Janeiro: Paz e Terra, 1991. 200 p.

_. Burke. New York: Hill and Wang, 1980. 83 p. (Past Masters Series).

—. Democratic theory: essays in retrieval. London: Clarendon Press, 1973. 255 p.

- Liberty and property: political ideology in Eighteenth-Century Britain (Book Review). The Journal of Modern History, v. 51, n. 2, Technology and War, p. 347348, Jun., 1979.

- Social credit: the English Origins (Book Review). The Journal of Modern History, v. 46, n. 2, p. 351-352, Jun., 1974.

- The economic penetration of political theory: some hypotheses. Journal of the History of Ideas, v. 39, n. 1, p. 101-118, Jan.-Mar. 1978.

. The liberal politics of John Locke (Book Review). Political Science Quarterly, v. 86, n. 1, p. 132-133, Mar., 1971.

- Voluntary associations within the state, 1900-1934; with special reference to the place of trade unions in relation to the state in Great Britain. Thesis. The London School of Economics and Political Science. London, 1935. 326 p.

Texto recebido em 14.01.04 e aprovado em 30.03.04 